\title{
Evaluating a sudden brake warning system: effect on the response time of the following driver
}

\author{
Robert B. Isler\#, Nicola J. Starkey, and Margaret A. Drew \\ Traffic and Road Safety Research Group \\ Psychology Department \\ University of Waikato \\ Hamilton, New Zealand
}

\begin{abstract}
This study used a video-based braking simulation dual task to evaluate the effectiveness of a Sudden Brake Warning System (SBWS) of a leading private passenger vehicle on the response time of the following driver. The primary task required the participants $(\mathrm{N}=$ 25, 16 females, full NZ licence holders) to respond to sudden braking manoeuvres of a lead vehicle during day and night driving, wet and dry conditions and in rural and urban traffic, while concurrently performing a secondary tracking task, simulating the steering of real driving. The SBWS in the lead vehicle consisted of a g-force controlled activation of the hazard lights in addition to the standard brake lights. Overall, the results revealed that responses to the braking manoeuvres of the leading vehicles when the hazard lights were activated by the warning system were $0.34 \mathrm{~s}$ faster compared to the standard brake lights. At $50 \mathrm{~km} / \mathrm{h}$, this would translate to a stopping distance saving of $4.7 \mathrm{~m}$ which would have the potential of reducing the number and severity of rear-end crashes. The warning system was particularly effective when the simulated braking scenario of the leading vehicle did not require an immediate and abrupt braking response. Given this, the SBWS may also be beneficial for allowing smoother deceleration, thus reducing fuel consumption. Furthermore, the warning system appeared to be equally effective during night / day and in wet / dry conditions. These findings call for a naturalistic study in order to test this new technology in 'real world' braking situations.
\end{abstract}

Keywords: Driving; rear-end collision; brake lights; stopping distance; dual task \# Correspondence author at: Department of Psychology, Faculty of Arts and Social Sciences, University of Waikato, Private Bag 3105, Hamilton: Tel. +64 78384466 ext 8401; Fax: +64 78585132.

E-mail address: r.isler@,waikato.ac.nz 


\section{Introduction}

It is estimated that worldwide, $25 \%$ of all crashes are rear-end collisions which are most often caused by driver inattention, following too closely, or looking at the wrong place at the wrong time (Wierville et al., 2006). In New Zealand, there were a total of 1309 rear-end collisions reported in 2007 to the police. The human consequences of which were 9 fatalities, 86 seriously injured and 1672 people sustaining minor injuries. The majority of these crashes (801) occurred on urban roads during hours of daylight with only 164 (20.5\%) occurring during periods of darkness. Although there were fewer rear-end crashes on rural roads (499), a higher proportion were during hours of darkness $(111 ; 22 \%)$ and there were six fatalities on rural roads (two during hours of darkness) compared with only three in urban areas, one of which occurred during hours of darkness (Ministry of Transport, 2008).

When factors contributing to all crashes in New Zealand in 2007 are examined, it has been estimated that 1479 crashes occurred due to driver inattention or division of attention, and of these, by far the biggest majority (860) were due to a failure of the driver to notice the car in front slowing, stopping or having stopped. A further 65 of the crashes resulting from insufficient attention were deemed to be due to a lack of awareness of the indication signal of the vehicle in front (Ministry of Transport, 2008).

This situation is not unique to New Zealand. The ' 100 car naturalistic study' continuously monitored day to day driving behaviour in instrumented cars over a year in the U.S. (Klauer et al., 2006; Neale et al., 2005). They found that $78 \%$ of crashes and $65 \%$ of near crashes could be attributed to driver inattention, with young drivers (18-20 years) being disproportionately involved in distraction related crashes. During the study period, 15 rear end collisions occurred, 380 near collisions, and 5783 incidents (greater than any other category of event), of which $93 \%$ of the rear end collisions involved driver inattention (not looking at road in front).

One proposed solution to this problem is the introduction of an alternative form of brake light system which aims to improve the reaction/braking time of the following vehicle by being more effective at capturing the attention of the driver. Various different types of system have been proposed and evaluated including brake lights which illuminate when the driver removes pressure from the accelerator (Shinar, 2000), 
additional brake lights which are activated only in emergency braking situations ( $\mathrm{Li} \&$ Milgram, 2008), brake lights which increase in size and luminance as the deceleration rate increases (Gail et al., 2001) and flashing brake lights (e.g., Voevodsky, 1974).

A landmark field study was conducted in 1974 using a fleet of San Francisco taxi cabs, where a number of the fleet were fitted with a deceleration warning light system, centre mounted on the rear of the vehicle (Voevodsky, 1974). This warning light was activated by the use of the brake pedal and pulsed at a rate that increased exponentially with the increase in gravity force generated by the deceleration. Over a twelve month period, this trial saw a decrease in the rear end collision rate from the 8.91 collisions per million miles over a total of 7.2 million miles for the control group (not fitted with the warning light), to 3.51 collisions per million miles over a total of 12.3 million miles for those fitted with the warning light. The crash rate for the control group over this time was consistent with previous data, in that it was comparable to the 1971 figures of 8.89 crashes per million miles over 21.5 million miles, and was close to the five year mean rate of 7.9 crashes over 125 million miles in the five years prior to 1972. This trial also resulted in a reduction in the driver injury rate from 1.67 per million miles for those in the control group to only 0.67 for those driving vehicles fitted with the warning light, and a drop in the cost of vehicle repairs from US\$1,041 per million miles to \$398.

Although these reductions were significant in themselves, given the more recent escalation in health and vehicle maintenance costs, the reductions in personal injury and vehicle repair costs achieved in the San Francisco trial would be even more significant in today's terms.

The positive effects of an enhanced braking system have also been demonstrated in a 'real world' situation where two alternative prototypes were tested (Wierwille et al., 2006). The first prototype consisted of an oscillating narrow beam lamp and the second was an alternating pair of lamps. In a situation where the drivers were given a secondary 'mildly distracting' task to perform while driving, both alternative rear lighting systems produced significantly improved reaction times in comparison to the standard rear lighting system. This effect was evident for both brake activation time and time to come to a full stop. In this experiment, it was estimated that driver responses were improved by 0.25 to $0.35 \mathrm{~s}$, which at $45 \mathrm{miles} / \mathrm{h}(72.4 \mathrm{~km} / \mathrm{h})$ corresponds to $5-7 \mathrm{~m}$ additional stopping 
distance, a figure which is, however, dependent on actual speed and various other factors which would characterise each particular situation.

For a brake light system to be most effective, it must be capable of capturing the attention of the peripheral visual system, as a driver's attention is frequently diverted from the road ahead by the numerous distracters present in the driving environment (Summala et al., 1998). Such a system must, in the first instance, be easily distinguished from its background context (Berg et al., 2007). However, a simple change in colour, detected primarily by the central visual system, does not attract attention as quickly as motion or changes in luminance. These changes are detected primarily by the faster processing peripheral visual system which responds selectively to abrupt changes in visual stimuli (Franconeri et al., 2005; Theeuwes, 1995).

Thus, as the peripheral visual system is more efficient at detecting motion and luminance changes, a braking light system characterized by flicker or oscillation should be more effective than a static light system. There is some support for this, with decreased reaction times ( $25-50 \mathrm{~ms}$ improvement) in response to brake lights flashing at $4 \mathrm{~Hz}$ (Gail et al., 2001), and $20 \mathrm{~Hz}$ (14 - $29 \mathrm{~ms}$ improvement) compared to static lights in simulated car driving tasks (Berg et al., 2007). Similar improvements in reaction time were observed with motorcycles when the brake lights were supplemented with flashing indicator lights $(1.5 \mathrm{~Hz})$ both in the laboratory and on the road in bright sunlight and during night-time driving (Tang, 2003). However, Alferdinck (2004) failed to find a beneficial effect of either $1.5 \mathrm{~Hz}$ or $5 \mathrm{~Hz}$ flashing lights positioned as a fog lamp or as brake lights but this may be due to their unusual experimental set-up.

Thus, research evidence to date suggests that a sudden brake warning system based on flashing lights could be advantageous in terms of reducing the number of rear end crashes. Furthermore, if the system not only attracted drivers' attention, but also provided an indication of braking intensity, this would enable following drivers to brake early and drive more smoothly, reducing fuel consumption (Metz, Davidson, \& Bosch, 2007). Indeed, one of the four Eco-Drive rules is to "think ahead and drive evenly; avoid unnecessary braking and gear changing" (QUAD, 2004). Therefore, along with a reduction in crash numbers, a more effective (attention captivating) braking system 
would facilitate a reduction in human cost (injury or death), the associated health costs, as well as fuel costs and not insignificant vehicle maintenance costs.

The current research was conducted to evaluate the effect of a Sudden Brake Warning System (SBWS) on the response time of the following driver. The system was an electronic safety device that monitored the deceleration of the vehicle to which it was fitted. It was activated when certain deceleration thresholds were met during a sudden stop, causing the hazard warning lights to flash on two different frequencies (2 Hz and 5 $\mathrm{Hz}$ ) depending on the threshold, indicating a hazard for the following driver. A laboratory and video-based braking dual task was used to record the response times of participants when the leading passenger vehicle was braking, activating the SBWS in addition to the standard braking lights during simulated, day and night driving scenarios and under wet and dry conditions. These response times were then compared with those in control braking conditions, using a within subject design, when only the standard braking lights were activated,

\section{Method}

\subsection{Participants}

A total of 25 participants volunteered to take part in this evaluation study and received a $\$ 10$ petrol voucher as a token of appreciation for their participation. Sixteen were female and the remaining nine were male. The mean age of the participants was 26 years $(\mathrm{SD}=9.2)$ and ranged from 18 to 52 years. All participants held a full New Zealand drivers license and the mean length of time the license had been held was 89 months, ranging from 10 months to 34 years.

\subsection{Materials and Measures}

A computer based digital video system was used to display the simulated videobased dual braking task on a $800 \mathrm{~mm}$ (32inch) computer monitor, which was viewed from the perspective of a driver following a private passenger vehicle (the 'lead vehicle'). The participants were seated approximately $750 \mathrm{~mm}$ in front of the screen, in a small sound proof laboratory and had access to a computer 'mouse' device. 
The dual braking task was specifically designed and software engineered for this study. It consisted of a primary braking simulation task and a secondary tracking task. The braking simulation task involved watching video-based driving scenarios (500 x 180 $\mathrm{mm}$ embedded in a bright blue frame), seen from the perspective of a driver, following the lead vehicle, but there was no steering or speed control required. The task consisted of pressing the mouse button each time the participant felt a braking response was required in order to keep a safe following distance from the lead vehicle or to avoid a rear-end collision. Pressing the mouse button caused a braking sound and the bright blue frame around the video simulation changed colour to purple. For each braking situation, a predetermined 'response window' was defined as the critical period during which the participant was expected to respond by clicking the mouse button. It started from the earliest point of time when a braking situation became visible (i.e., when the lead vehicle was braking) and ended at the point when the braking response was considered as too late to avoid a rear-end collision. If a mouse click was detected during a response window, the corresponding response time was taken from the start of the critical period to the time when the mouse press occurred.

The secondary task required the participants to carry out a tracking task, simulating the steering in real driving. As can be seen in Fig. 1, the tracking task consisted of a stationary rectangle $(130 \times 80 \mathrm{~mm})$ that was digitally superimposed on to the video-based traffic simulation, in the central lower area of the driving scenario, approximately at the location of the road ahead. The participants were required to keep a small moving target $(5 \times 5 \mathrm{~mm}$, speed approx $10 \mathrm{~mm} / \mathrm{s})$ within a square $(30 \times 30 \mathrm{~mm})$. The movement of the square was controlled by the participants via the computer mouse device. The moving target was contained within the stationary rectangle, bouncing off its sides like a ball would on a billiard table. Each time the target was 'miss-tracked' by the participants and 'escaped' from the square, a low pitched 'peep' sound was produced and the frame around the simulation changed colour from blue to red for $500 \mathrm{~ms}$, alerting the participants to the tracking error. These occasions were recorded as the dependent variable 'number of tracking errors' for each trial. A second dependent variable 'tracking error time' was derived from the amount of time that the target spent outside the square for each trial. 


\section{Figure 1 here}

\subsection{Sudden Brake Warning System.}

The Sudden Brake Warning System (SBWS, commercially known as 'BrakeAlert') was manufactured by DataBrake International Ltd, New Zealand and consists of a small credit card size, $20 \mathrm{~mm}$ thick electronic interface device that can be installed in any vehicle. The system involves an accelerometer and each time the vehicle reaches certain braking g-force thresholds, the interface activates the hazard braking lights. Once a braking g-force threshold of 0.8 is reached, the hazard lights start flashing at the rate two $\mathrm{Hz}$ ('low frequency flashing mode') and when a g-force threshold of 0.9 is reached (very abrupt deceleration), the rate is increased to five $\mathrm{Hz}$ ('high frequency flashing mode').

\subsection{Video-based braking scenarios}

More than 120 traffic situations were filmed using a Sony mini digital HDD video camera (normal $52 \mathrm{~mm}$ lens) mounted on a fixed tripod beside the driver in a dedicated research vehicle that had the front passenger seat removed. A Nissan Cifero was used as the 'lead vehicle' which had a SBWS installed and was staging the various braking scenarios which were filmed by the following research vehicle with the video camera.

Fourteen video test clips were selected which were between 20 and $30 \mathrm{~s}$ long and covered a wide range of braking situations (see Table 1 for a brief description of each scenario). These included, rural (9 clips) and urban traffic areas (5), wet (2) and dry conditions (12), each of which triggered a g-force threshold that activated the hazard lights in either the low (9) or high frequency flashing mode (5).

Eight of the selected test clips (series A, see Table 1) required an immediate 'braking response' (mouse click) from the participants. These clips had response windows open for up to $1.5 \mathrm{~s}$ during which 'abrupt braking responses' were required to avoid what would be 'rear-end collisions' in a real driving situation. The remaining six test clips (series B, see Table 1) opened longer response windows and the participants were required to 'brake' within time periods of up to $5 \mathrm{~s}$. For these scenarios, early detection of the lead vehicle braking would have allowed less abrupt braking responses with smoother 
deceleration due to the greater available safety margins, as recommended for defensive and eco-driving.

The 14 selected test clips were sent to a professional post-production company which digitally removed the flashing hazard lights to create 14 matched control clips, showing the same braking situations but with only the standard braking lights visible. From the pool of 120 traffic scenarios, an additional 14 scenarios were selected where no braking response was required. In seven 'no braking' scenarios, the SBWS was activated but the lead vehicle was either very far ahead or off the road and was therefore not a hazard. In the remaining seven 'no braking' scenarios, the SBWS was never activated, but in some occasions the standard braking lights of the lead vehicle were visible but the participants were not required to respond as the lead vehicle was not in their driving path. The idea of the 'no-braking' scenarios was to avoid the participants anticipating a braking response for every scenario which would have simplified the braking/no braking decision process.

Table 1. Short description of the braking scenarios (14 test clips):

$\mathrm{A}=$ Scenario number; $\mathrm{B}=$ Road type and characteristics; $\mathrm{C}=$ Reason for the lead vehicle to brake, $\mathrm{D}=$ Approx. speed $(\mathrm{km} / \mathrm{h})$ of the lead vehicle just before the braking response was required from the participants; $E=$ Response window (s); F = Day (D) or Night (N), Wet (W) or Dry (D); $\mathrm{G}=$ Frequency of flashing hazard lights, $\mathrm{L}=$ low $(2 \mathrm{~Hz}), \mathrm{H}=$ high $(5 \mathrm{~Hz})$.

\begin{tabular}{|c|c|c|c|c|c|c|}
\hline \multicolumn{7}{|c|}{ Test clip series A (response windows open for $1.5 \mathrm{~s}$ ) } \\
\hline A & $\mathrm{B}$ & $\mathrm{C}$ & $\mathrm{D}$ & $\mathrm{E}$ & $\mathrm{F}$ & $\mathrm{G}$ \\
\hline 1 & Urban, build up area & Approaching roundabout & 50 & 1.5 & $\mathrm{~N}, \mathrm{D}$ & $\mathrm{H}$ \\
\hline 2 & $\begin{array}{l}\text { Urban, build up area, oncoming } \\
\text { traffic and street lights }\end{array}$ & No apparent reason & 50 & 1.5 & $\mathrm{~N}, \mathrm{D}$ & $\mathrm{H}$ \\
\hline 3 & Rural, straight, street lights & No apparent reason & 70 & 1.5 & N.D & $\mathrm{L}$ \\
\hline 4 & Rural, straight, no street lights & No apparent reason & 70 & 1.5 & $\mathrm{~N}, \mathrm{D}$ & $\mathrm{L}$ \\
\hline 5 & Straight road & Stop traffic sign & 70 & 1.5 & $\mathrm{~N}, \mathrm{D}$ & $\mathrm{L}$ \\
\hline 6 & Rural, curves, some traffic & No apparent reason & 70 & 1.5 & $\mathrm{D}, \mathrm{D}$ & $\mathrm{L}$ \\
\hline 7 & Rural, straight & Stop trafficsign & 50 & 1.5 & $\mathrm{D}, \mathrm{D}$ & $\mathrm{L}$ \\
\hline 8 & Urban, parked cars left side & Pedestrian crossing & 50 & 1.5 & $\mathrm{D}, \mathrm{W}$ & $\mathrm{H}$ \\
\hline \multicolumn{7}{|c|}{ Test clip series B (response windows open for least $2 \mathrm{~s}$ and up to $5 \mathrm{~s}$ ) } \\
\hline A & $\mathrm{B}$ & $\mathrm{C}$ & $\mathrm{D}$ & $\mathrm{E}$ & $\mathrm{F}$ & G \\
\hline 9 & $\begin{array}{l}\text { Rural, gentle bends - no other } \\
\text { traffic and no street lights }\end{array}$ & Sharp curve warning sign & 40 & 3.5 & $\mathrm{~N}, \mathrm{D}$ & $\mathrm{L}$ \\
\hline 10 & Rural road, straight flat & No apparent reason & 50 & 5 & $\mathrm{D}, \mathrm{D}$ & $\mathrm{L}$ \\
\hline 11 & $\begin{array}{l}\text { Rural, traveling over the brow } \\
\text { of a hill }\end{array}$ & $\begin{array}{l}\text { Standing still on top of } \\
\text { brow, no braking }\end{array}$ & 45 & 4 & $\mathrm{~N}, \mathrm{D}$ & $\mathrm{H}$ \\
\hline 12 & $\begin{array}{l}\text { Urban, one way, parked cars on } \\
\text { left side }\end{array}$ & Give way traffic sign & 50 & 2 & $\mathrm{D}, \mathrm{W}$ & $\mathrm{L}$ \\
\hline 13 & Rural, straight, no street lights & No apparent reason & 60 & 2 & $\mathrm{~N}, \mathrm{D}$ & $\mathrm{H}$ \\
\hline 14 & Rural, straight & No apparent reason & 70 & 5 & $\mathrm{D}, \mathrm{D}$ & $\mathrm{L}$ \\
\hline
\end{tabular}




\subsection{Procedure}

Firstly, the participants were given a brief outline of the nature of the study. It was explained that after they completed a short demographics questionnaire they would be presented with 43 video clips, including a practice clip, each of which they would activate with a mouse click when they were ready. They were then instructed to click the mouse button in each situation where they would normally apply the brakes, and the number of times they needed to 'brake' could differ for each clip. They were also instructed how to perform the secondary task and informed that their data could not be included in the study if they accumulated too many tracking errors.

They were then seated in front of the computer monitor and were given a flat surface to place on their lap on which to operate the mouse. When they were ready the participants activated the practice video with a mouse click. They repeated this practice clip until they were comfortable with the procedure, at which time the 42 experimental clips were presented. At the conclusion of the session the participants were thanked for their participation and were given a $\$ 10$ petrol voucher.

\section{Results}

All 25 participants completed the video-based dual braking task and provided 682 valid braking response times for the primary braking task and also completed a short demographics questionnaire. There were 18 missing braking response times $(0.02 \%)$ in the data file either because the mouse clicks were not recorded due to a technical issue or to the participants failing to respond.

The performance of the participants in the secondary task of the dual task, which simulated the steering task in real driving, was analysed first in order to determine if all participants divided their attention similarly between the two tasks. That is, was a reasonable effort made to maintain performance in the secondary tracking task.

Next, the 'braking response' performance of the participants in the primary task was analysed. First, all response times for the 14 matched test-control braking scenarios - with the lead vehicle braking and activating the SBWS and the corresponding matched control 
scenarios with the lead vehicle braking with only the standard braking lights visible, were compared. The 'non braking' scenarios (9) were not analysed as they had no response times associated with them.

After the overall analysis, the test clips for the braking scenarios in series A with short response window openings $(1.5 \mathrm{~s})$ were analysed separately from the test clips, series B, which had longer response windows ( $2 \mathrm{~s}-5 \mathrm{~s})$. A within-subject design was used as each participant provided their own control data and one-way repeated measures ANOVAs were used as inferential statistics in order to determine significance (alpha level of significance was set at 0.05; a 'trend' was defined a $\mathrm{p}>0.05$ but $\mathrm{p}<0.1$ ), 95\% confidence levels, standard deviations and standard errors were used as variability measures. Partial eta squared $\left(\eta_{\mathrm{p}}{ }^{2}\right)$ indicated effect size. Traditionally, $\eta_{\mathrm{p}}{ }^{2}$ values of .01 , 0.06 and .14 represent small, medium and large effect sizes (Cohen, 1988). Observed power was also obtained.

\subsection{Secondary task}

All participants performed well in the secondary tracking task with a mean number of tracking errors of $\mathrm{M}=0.52(\mathrm{SD}=0.46)$ per trial and a mean tracking error time of $\mathrm{M}=$ $0.21 \mathrm{~s}(\mathrm{SD}=0.34)$. Over the 42 trials ( 28 braking trials and 14 non braking trials $), 14$ participants had less than 10 tracking errors, 9 had between 10 and 20 errors and only 4 had more than 20 errors $(21,23,49,57)$. The 23 participants who had less than 20 tracking errors had a total error tracking time of less than $10 \mathrm{~s}($ Mean $=4.3 \mathrm{~s}, \mathrm{SD}=2.07)$ and the 4 participants who had more than 20 tracking errors had total tracking error times of more than $10 \mathrm{~s}(11.2 \mathrm{~s}, 14.3 \mathrm{~s}, 30.5 \mathrm{~s}, 44.1 \mathrm{~s})$. Further inspection of the data revealed that two of those participants who had unusually long overall tracking error times $(>30$ seconds) did not continue the secondary tracking task once they delivered a braking response. It was concluded that all participants were making a good effort to maintain their performance in the secondary task and therefore completed the primary task under divided attention conditions.

\subsection{Primary task}

3.2.1. Overall effect of the Sudden Brake Warning System 
The analysis of the data for the primary task revealed that overall, the participants responded faster when the lead vehicle braked with the hazard lights activated by the Sudden Brake Warning System SBWS (overall mean response time $\mathrm{M}=1.41 \mathrm{~s}$; standard deviation $\mathrm{SD}=0.58$ ) compared to the control simulations when only the standard braking lights were visible $(\mathrm{M}=1.75 \mathrm{~s} ; \mathrm{SD}=0.99)$. This means that overall and on average, the participants responded $0.34 \mathrm{~s}$ faster to the braking manoeuvre of the lead vehicle when the SBWS was activated. A one-way (SBWS versus non SBWS) repeated measures ANOVA confirmed significant shorter response times of the participants when the SBWS was activated, $F(1,13)=4.73, \mathrm{p}<0.05$, a large effect size $\eta_{\mathrm{p}}{ }^{2}=0.27$, and an observed power $=0.52$.

\subsubsection{Braking test scenarios series A}

The braking test scenarios 1-8 (series A, see Table 1) each required an immediate 'braking response' via mouse click with a response window open for only $1.5 \mathrm{~s}$. Figure 2 shows the mean response times and variability measures of the participants for those test scenarios.

\section{Figure 2 here}

The figure shows that on average, the participants responded faster to braking manoeuvres of the lead vehicle when the SBWS activated the hazard lights, except for two scenarios ( 2 and 8 ). The mean response time of the 25 participants for the braking manoeuvres with an activated SBWS was $\mathrm{M}=1.01 \mathrm{~s}(\mathrm{SD}=0.18)$ and for the 8 corresponding scenarios with only the standard braking lights activated was $\mathrm{M}=1.11 \mathrm{~s}$ $(\mathrm{SD}=0.15)$. This means that overall for the braking scenarios of series $\mathrm{A}$, the participants responded on average $0.10 \mathrm{~s}$ faster when the leading car was braking with the SBWS activated than without the SBWS.

A one-way (SBWS vs non SBWS) repeated ANOVA comparing the mean response times of the 8 scenarios from series A revealed a near statistically significant effect (a 'trend') of the SBWS with $F(1,7)=4.58, \mathrm{p}=0.07$, a large effect size of $\eta_{\mathrm{p}}{ }^{2}=0.40$ and a 
statistical power of 0.45 . The biggest effect of the SBWS was revealed by test scenario 3 , which was filmed at night, when the lead vehicle abruptly braked for no apparent reason. For this scenario, the participants responded on average 0.25 seconds faster to the braking of the lead vehicle with the SBWS activated $(\mathrm{M}=0.86 \mathrm{~s}, \mathrm{SD}=0.32)$ compared to the braking with only standard braking lights visible $(\mathrm{M}=1.11 \mathrm{~s}, \mathrm{SD}=0.34$, a difference which reached significance with $\mathrm{F}(1,24)=19.20, \mathrm{p}<0.01$, a large effect size $\eta_{\mathrm{p}}{ }^{2}=0.45$, and observed power of 0.98 . None of the other 7 braking scenarios of the series A revealed any significant effects of the SBWS.

There were no clear differences in the effectiveness of the SBWS when day and night driving scenarios were compared (see Fig. 2). Although the only significant decrease in response time was observed in a night time scenario (3), this was not consistent across all night time scenarios.

Interestingly, there were two test braking scenarios (night driving scenario 2 and day driving scenario 8) for which the participants had longer average response times (although not significantly) when the lead vehicle was braking with the SBWS compared to the standard braking lights. In both of these scenarios, the SBWS triggered the high frequency flashing mode of the hazard lights $(5 \mathrm{~Hz})$, indicating that compared to standard braking lights such high frequency flashing did not necessarily lead to faster response times.

\subsubsection{Braking test scenarios series B}

The braking test scenarios 9-14 (series B, see Table 1) did not always require an immediate 'braking response' as they had response window openings of least $2 \mathrm{~s}$ and up to $5 \mathrm{~s}$. Fig. 3 shows the mean response times and variability measures of the participants for these scenarios. Similar to the braking test scenarios, series A, this figure shows that on average the participants responded faster to braking manoeuvres of the lead vehicle when the SBWS activated the hazard lights. The two exceptions were scenarios 13 and 14.

\section{Figure 3 here}


The mean response time of the participants for the braking manoeuvres in series B with an activated SBWS was $\mathrm{M}=1.96 \mathrm{~s}(\mathrm{SD}=0.49)$ and for the 6 corresponding scenarios with only the standard braking lights activated was $\mathrm{M}=2.62 \mathrm{~s}(\mathrm{SD}=0.98)$. Thus, for the series B test scenarios, the participants responded on average $0.66 \mathrm{~s}$ faster when the leading car was braking with the SBWS activated than without.

A one-way (SBWS vs non SBWS) repeated measures analysis of variance (ANOVA) comparing the mean response times for the 6 braking scenarios from the series B revealed a near statistically significant effect of the SBWS with $\mathrm{F}(1,5)=4.42, \mathrm{p}=0.09$, a large effect size of $\eta_{\mathrm{p}}{ }^{2}=0.47$ and a statistical power of 0.40 .

The most profound effects of the SBWS were revealed in braking scenario 10 (rural road, daylight driving, lead vehicle braked for no apparent reason), followed by scenario 12 (rural road, night driving, lead vehicle braked because of sharp curve traffic sign), and 9 (urban, daylight driving, lead vehicle braked because of give way traffic sign). For scenario 10 , the participants responded on average 1.36 seconds faster to the braking of the lead vehicle with the SBWS activated $(\mathrm{M}=2.42 \mathrm{~s}, \mathrm{SD}=1.29)$ compared to the braking with only standard brake lights visible $(\mathrm{M}=3.78 \mathrm{~s}, \mathrm{SD}=1.76)$, a difference which reached significance with $\mathrm{F}(1,22)=13.38, \mathrm{p}<0.01$, large effect size $\eta_{\mathrm{p}}{ }^{2}=0.38$, and observed power of 0.98 .

For scenario 12 (and scenario 9), they responded on average $1.06 \mathrm{~s}$ faster (scenario 9: $0.66 \mathrm{~s}$ faster) when the SBWS was activated with $\mathrm{M}=2.38 \mathrm{~s}, \mathrm{SD}=1.23$ (scenario $9: \mathrm{M}$ $=1.87 \mathrm{~s}, \mathrm{SD}=1.40)$ compared to the standard braking lights with $\mathrm{M}=3.44 \mathrm{~s}, \mathrm{SD}=1.38$ (scenario 9: $\mathrm{M}=2.53 \mathrm{~s}, \mathrm{SD}=1.33$ ) with $\mathrm{F}(1,22)=78.28, \mathrm{p}<0.01$, large effect size size $\eta_{\mathrm{p}}{ }^{2}=0.29$ and observed power of 0.86 (scenario 9: $\mathrm{F}(1,22)=4.96, \mathrm{p}<0.05$ large effect size $\eta_{\mathrm{p}}{ }^{2}=0.19$, observed power of 0.53 ) None of the other three braking scenarios revealed any significant effects of the SBWS.

Fig. 3 revealed no clear patterns for the effects of the SBWS comparing the response times for the night driving scenarios with those of the day driving scenarios with one night driving scenario (9) revealing an effect of the SBWS while the two other scenarios did not (11 and 13), and for two day driving scenarios (10 and 12), the SBWS had an effect while there was no effect for another (14). 
There were two pairs of test scenarios (night driving scenario 13 and day driving scenario 14) for which the participants had the same or longer response times (although not significantly) when the lead vehicle was braking with the SBWS compared to standard brake lights. Furthermore, the low frequency flashing $(2 \mathrm{~Hz})$ appeared to be more effective than the high frequency flashing $(5 \mathrm{~Hz})$, as significant improvements in response time were observed only in the low frequency mode (see Fig. 3).

\section{Discussion}

This study was conducted in order to compare the time taken to respond to a Sudden Brake Warning System (SBWS) with the time taken to respond to standard brake lights. A video-based dual task was used, which consisted of a braking simulation task (mouse click) and a secondary tracking task. This design was chosen in order to most closely replicate 'real world' conditions, in which a driver's attention is rarely focused solely on the road ahead.

Initially, it was ascertained that the participants paid considerable attention to the secondary tracking task, with an average of less than one tracking error per video clip. This indicated that the simulated braking task was not performed under the unrealistic condition of being the sole focus of the participant's attention. In a real driving situation, children in the back seat, unpredictable pedestrians, radio, cell phones and numerous environmental factors can all divert a driver's attention from the primary task. However, even with the participant's attention partially diverted by the secondary task, it was still evident, that over all the conditions represented in the video based braking scenarios, response time following the activation of the SBWS was faster than when standard brake lights were applied.

Although the average difference in braking response time was only $0.34 \mathrm{~s}$, at $50 \mathrm{~km} / \mathrm{h}$, this translates to a stopping distance saving of $4.7 \mathrm{~m}$. At $100 \mathrm{~km} / \mathrm{h}$ the saving is even greater at $9.5 \mathrm{~m}$. Obviously in the real environment, each driving situation is different and these differences would influence the exact stopping distance, however it is evident that the distance saved has the potential to considerably reduce the number of rear end collisions. These findings closely mirror the findings of Wierwille et al. (2006), who used 
an oscillating brake light system to demonstrate improvements of between $0.25 \mathrm{~s}$ and $0.35 \mathrm{~s}$ in the brake time response when compared with response time to standard brake lights. Similarly, flashing lights on motorbikes were also able to reduce brake times by 80 ms on average (Tang, 2003).

The current findings are also consistent with data from other simulated driving studies. Gail et al, 2001 found improvements of $25-50 \mathrm{~ms}$ in response to a $4 \mathrm{~Hz}$ flashing light compared to a static light whilst Berg et al., 2007 noted reaction time decreases of $14-29$ $\mathrm{ms}$ in response to a $20 \mathrm{~Hz}$ flashing light. This smaller difference could be due to the use of a higher frequency flicker $(20 \mathrm{~Hz})$ which is closer to the flicker fusion rate (approximately $30 \mathrm{~Hz}$ ) than the slower rates used in our study. Although there is some difference of opinion regarding the optimal 'attention capturing' flicker rate, optimal rates of between 3 to $10 \mathrm{~Hz}$ have been suggested (Berg et al., 2007).

When the driving scenarios were divided into those requiring an immediate response and those whose response windows were up to $5 \mathrm{~s}$, some differences became evident. For the 8 scenarios which had a response window of $1.5 \mathrm{~s}$, the average response time was faster when the SBWS was activated, but the average difference in response time between the two brake light systems was only $0.10 \mathrm{~s}$. However, the greatest effect of the SBWS in these short response time clips was seen in a night time scenario when the lead car braked for no apparent reason. For this condition the braking response time for the SBWS was on average $0.25 \mathrm{~s}$ faster than for the standard brake lights. Traveling at 100 $\mathrm{km} / \mathrm{h}$, this differential equates to a saving in stopping distance of $6.9 \mathrm{~m}$, an effect which could, in certain circumstances, save lives. Furthermore, in conditions of close following, where response window openings are short, any improvement in the time taken to make the appropriate response could be invaluable if a collision is to be avoided.

It was also evident that for two of these eight scenarios the response time for the SBWS was slightly slower than for the standard brake lights. In both of these two clips the higher flicker rate of the SBWS had been activated. Although the optimal flicker rate has not yet been ascertained, it could be expected that the slower flicker rate would be less effective than the faster rate, especially when an immediate response is required, as the slower rate would be indistinguishable from a static light for a perceptibly longer period than a more rapid flicker. This effect could be expected to be enhanced when 
focus is not directed solely at the road ahead and peripheral vision is required to pick up the warning signal. It therefore seems possible that for this study some video-based artifact has rendered the $5 \mathrm{~Hz}$ flicker rate less effective than the $2 \mathrm{~Hz}$ flicker rate, at least when the response window was only open for a short time period. As the viewing screen was not large, it may also be, however, that the participants' were able to keep focused primarily on the driving task, while low eccentricities of peripheral vision and a minimal level of attention were sufficient to the perform the tracking task. Finally, given the short response window openings, it is possible that the participants were not able to respond more quickly, irrespective of the braking stimuli.

For the six scenarios with longer response windows, the response time advantage of the SBWS was on average $0.66 \mathrm{~s}$. Again at $100 \mathrm{~km} / \mathrm{h}$, this translates into a stopping distance saving of $18.3 \mathrm{~m}$, which provides a considerable window of opportunity for the driver to assess the situation and make a non urgent, less abrupt braking response. Additionally, for three of these scenarios, the response time difference was sufficiently large as to be statistically significant. However, for two of the remaining three clips the response time difference was very small, and in both of these scenarios the faster flicker rate had been activated. Therefore, taking all scenarios together, it would seem, contrary to expectations, that the $5 \mathrm{~Hz}$ flicker did not result in the same response time advantage as the $2 \mathrm{~Hz}$ flicker rate.

The additional braking time window created by the use of the SBWS, especially in the less-urgent braking conditions, also provides motoring advantages from both defensive driving and eco driving standpoints. From a defensive driving standpoint, the earlier a driver becomes aware of a situation where some response is required the more effectively and safely that response can be executed. Additionally, when ample warning of the need for a braking response is given, the braking can be done incrementally rather than suddenly. This technique has been proven to be a much more fuel efficient method of slowing or stopping (Metz, et al., 2007; QUAD, 2004).

Overall, this study has demonstrated a significant advantage of the SBWS over the standard brake light system in reducing the time to respond to their activation. Given the prevalence of driver inattention and the resulting number of crashes, when the response time improvement of the SBWS is translated into stopping distance, the potential to avoid 
crashes and improve the road safety statistics is considerable. This system also has the advantage of being able to be installed in any car without requiring extensive modification to the vehicle.

There were several limitations associated with the current study which could be addressed in future research. Firstly, contrary to expectations, the higher frequency flashing mode did not seem as effective as the slower flicker. Whether this was due to the limited visual field requirements of the study, compared to the 180 degree plus range of distractions encountered in the driving environment, or whether it was some factor related to the video presentations, should be the subject of further research. In addition, the primary and the secondary tasks, simulating the braking and steering tasks were both conducted using a computer mouse and were dependent upon hand movements which may have had some limited ecological validity.

Nonetheless, these preliminary findings confirm the potential of sudden brake warning systems for improving drivers' response times to sudden braking manoeuvres of the lead vehicles. Furthermore, these findings call for naturalistic studies in order to test such devices in real braking situations and address some of the limitations of the current study.

\section{Acknowledgments:}

We would like to thank Andrew Malcolm for programming the dual task and the Data Brake for providing some funding for research assistance to conduct this evaluation study. 


\section{References}

Alferdinck, J.W.A.M. (2004). Evaluation of an emergency brake light display. TNO Report. http://www.unece.org/trans/doc/2004/wp29gre/TRANS-WP29-GRE-5302e.pdf.

Berg, W. P., Berglund, E. D., Strang, A. J., \& Baum, M. J. (2007). Attention-capturing properties of high frequency luminance flicker: Implications for brake light conspicuity. Transportation Research Part F: Traffic Psychology and Behaviour, 10(1), 22-32.

Cohen, J. (1988). Statistical power analyses for the behavioural sciences. NewYork: Lawrence Erlbaum Associates.

Enns, J. T., Austen, E. L., Di Lollo, V., Rauschenberger, R., \& Yantis, S. (2001). New objects dominate luminance transients in setting attentional priority. Journal of Experimental Psychology: Human Perception and Performance, 27(6), 1287-1302.

Franconeri, S. L., Hollingworth, A., \& Simons, D. J. (2005). Do New Objects Capture Attention? Psychological Science, 16(4), 275-281.

Gail, J., Lorig, M., Gelau, C., Heuzeroth, D., Sievert, W. (2001). Optimisation of rear signal pattern for reduction of rear-end accidents during emergency braking manoeuvres. Federal Highway Research Institute. http://www.bast.de/cln_007/nn_75106/DE/Publikationen/Berichte/unterreihe-f/20072000/f39.html.

Klauer, S.G., Dingus, T.A., Neale, V.L., Sudweeks, J.D., Ramsey, D.J., 2006. The Impact of Driver Inattention on Near Crash/Crash Risk: An Analysis Using the 100-Car Naturalistic Driving Study Data. National Highway Traffic Safety Administration, Washington, DC. 
Li, Z., Milgram, P. (2008). An empirical investigation of a dynamic brake light concept for reduction of rear-end collisions through manipulation of optical looming. Int. J. Human-Computer Studies, 66, 158-172.

Metz, B., Davidson, O., Bosch, P. (2007). Climate Change 2007: Working group III contribution to the fourth assessment report of the Intergovernmental panel on climate change. Cambridge University Press: p351.

Ministry of Transport. (2008). Yearly report of motor vehicle crashes in New Zealand 2007. Downloaded from http://www.transport.govt.nz/annual-statistics-2007/ 13 Feb 2009.

Neale, V.L., Dingus, T.A., Klauer, S.G., Sudweeks, J., Goodman, M. (2005). An Overview of the 100-car naturalistic study and findings. National Highway Traffic Safety Administration, Washington DC.

QUAD (2004). Summary: Evaluation of Eco-Drive Training Courses. Zurich. Downloaded from www.eco-drive.ch.

Shinar, D. (2000). Fleet study evaluation of an advance brake warning system. Human Factors, 42, 482-489.

Summala, H., Lamble, D., Laakso, M. (1998). Driving experience and perception of the lead car's braking when looking at in-car targets. Accid. Anal. And Prev.,30 (4), 401-407.

Tang, K.-H. (2003). A filed study validation of supplemental brake lamp with flashing turn signals for motorcycles. International Journal of Industrial Ergonomics, 31, 295-302. 
Theeuwes, J. (1995). Abrupt luminance change pops out; abrupt color change does not. Perception \& Psychophysics, 57(5), 637 - 644.

Wierwille, W.W., Lee, S.E., DeHart, M.C., Perel, M. (2006). Test road experiment on imminent warning rear lighting and signaling. Human Factors, 48 (3), 615-626.

Voevodsky, J. (1974). Evaluation of a deceleration warning light for reducing rear-end automobile collisions. Journal of Applied Psychology, 59(3), 270-273. 
Fig. 1. Sample screen shot of a video-based simulation of the braking dual task from the perspective of the driver following a lead vehicle which is braking. The secondary tracking task is also visible in the lower centre of the traffic scenarios, including the stationary rectangle, the user controlled square and the moving target

Fig. 2. Mean response times for the test scenarios 1-8 (series A) with the Sudden Brake Warning System (SBWS) activated (right) and only the standard braking lights visible (left), including standard errors and 95\% confidence intervals $(\mathrm{N}=$ night driving, $\mathrm{D}=$ day driving, $(\mathrm{H})=$ SBWS on high frequency flashing mode.

Fig. 3. Mean response times for test scenarios 9-14 (series B) with the Sudden Brake Warning System (SBWS) activated (right) and only the standard braking lights visible (left), including standard errors and 95\% confidence intervals $(\mathrm{N}=$ night driving , $\mathrm{D}=$ day driving, $(\mathrm{H})=$ SBWS on high frequency flashing mode. 


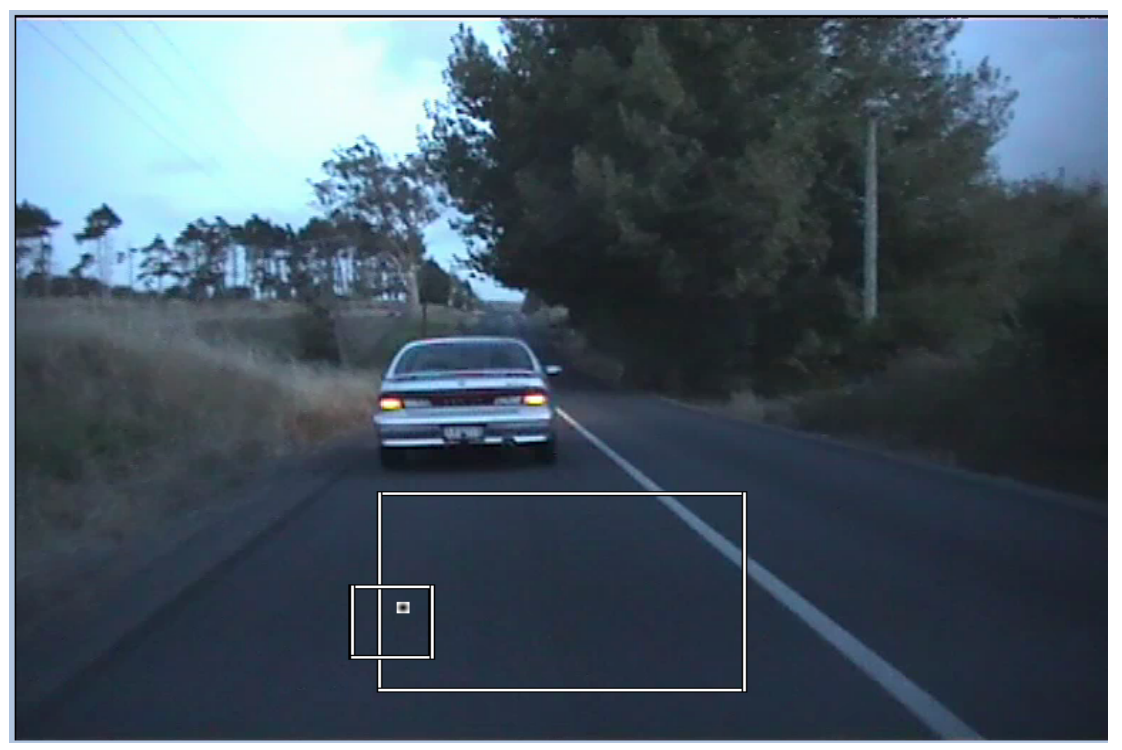

Fig. 1.

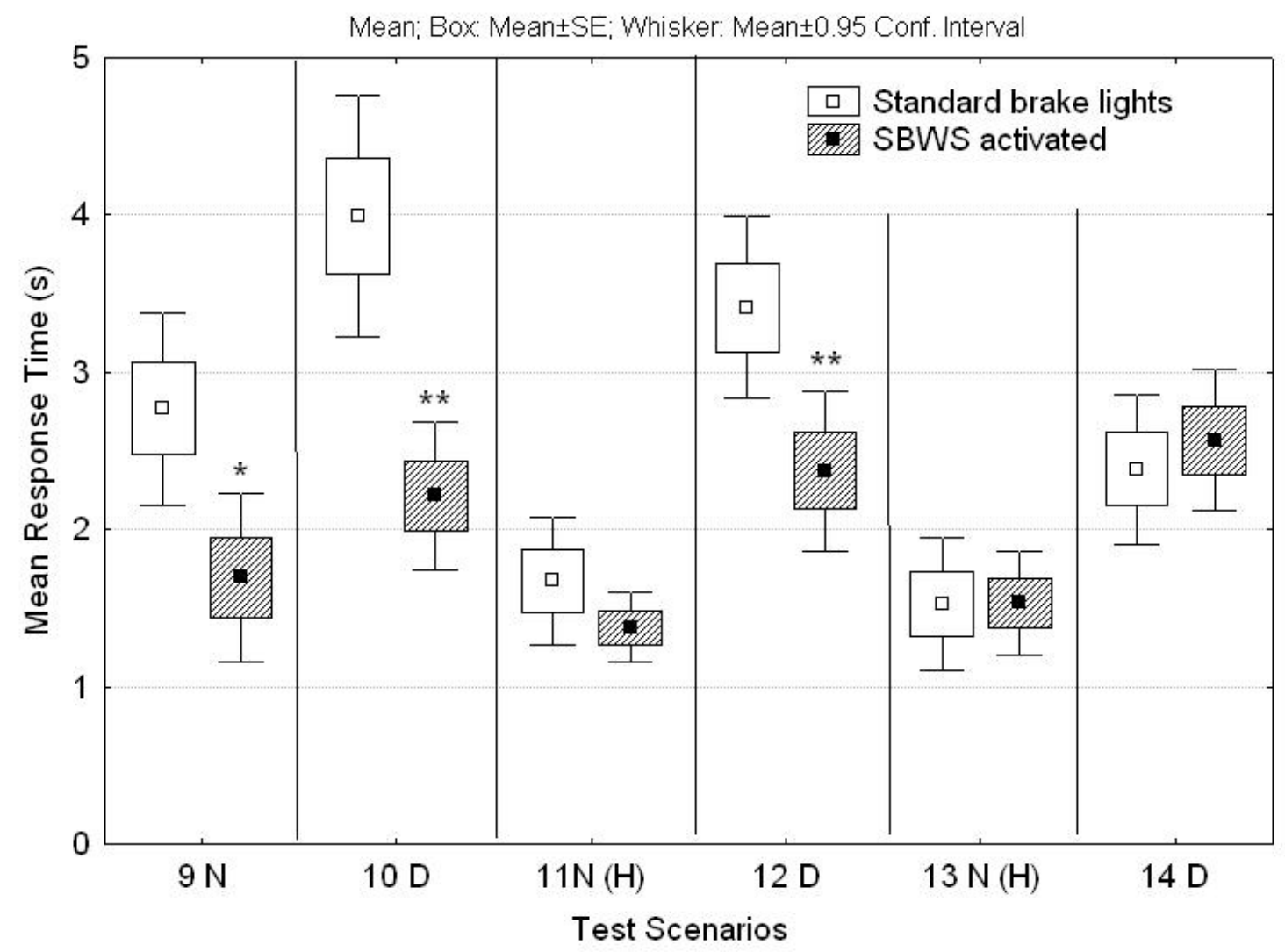

Fig. 2. 


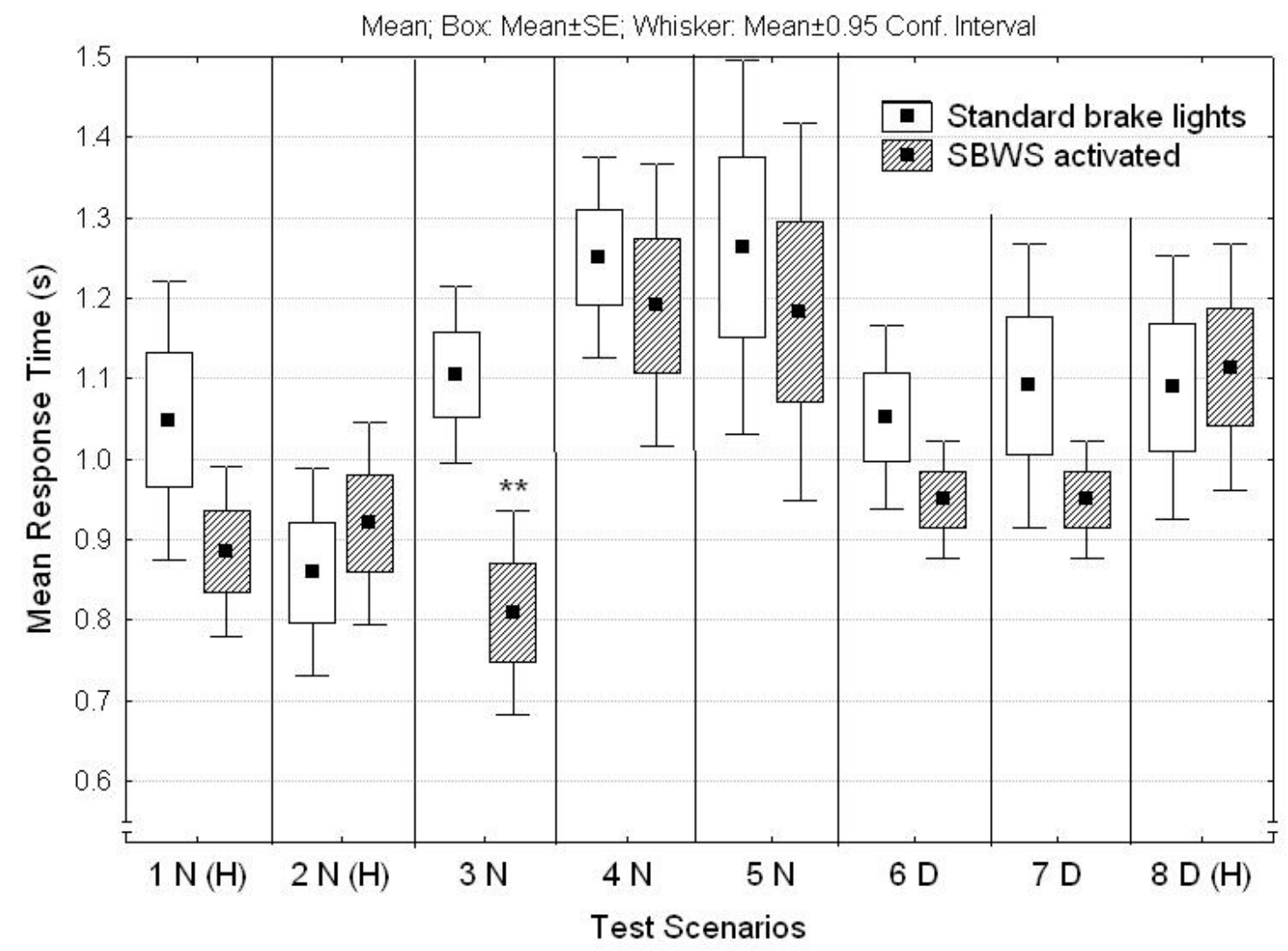

Fig. 3. 